\title{
Clostridium ramosum
}

National Cancer Institute

\section{Source}

National Cancer Institute. Clostridium ramosum. NCI Thesaurus. Code C86290.

A species of anaerobic, Gram positive, rod shaped bacteria assigned to the phylum

Firmicutes. This species is nonsporulating, urease, catalase and indole negative,

pyrrolidonyl negative, does not reduce nitrate, weakly ferments mannose and raffinose and may appear gram variable due to staining difficulty. C. ramosum is part of the RIC group of clostridium and is an opportunistic pathogen. 